\title{
BABEL - VISTA DOS ANACRONISMOS DA REVISTA
}

\author{
Luísa Cristina dos Santos Fontes
}

Em um de seus contos mais conhecidos, "A Biblioteca de Babel", que integra o livro Fiç̧ões - de 1944, Borges constrói uma "situação filosóficonarrativa", na expressão de Beatriz Sarlo ${ }^{1}$, para explicar a realidade como uma biblioteca sem fim que abriga uma quantidade também infinita de livros, em sua maioria, inúteis. Um dos bibliotecários, narrador do conto, explica que se supõe que cada volume contenha uma possibilidade de realidade, por isso a busca por alguém que consiga decifrar os volumes escritos em línguas desconhecidas. Talvez o cerne de toda a obra borgiana, na realidade (se é que essa expressão tem algum efeito falando de Borges), absolutamente presente em Ficções, mais ainda no conto "A Biblioteca de Babel", seja a questão do real e sua relação com a linguagem. "A Biblioteca de Babel" é o universo, um caos insolitamente ordenado e inesgotável, onde cada homem pode encontrar justificativas para sua própria existência. "Não há, na vasta Biblioteca, dois livros idênticos... a biblioteca é total e suas prateleiras registram todas as possíveis combinações dos vinte e tantos símbolos ortográficos (número, ainda que vastíssimo, não infinito), ou seja, tudo o que é dado a expressar: em todos os idiomas. Tudo: a história minuciosa do futuro, as autobiografias dos arcanjos, o catálogo fiel da Biblioteca, milhares e milhares de catálogos falsos, a demonstração da falácia do catálogo verdadeiro, o evangelho gnóstico de Basílides, o comentário desse evangelho, o comentário do comentário desse evangelho ..."

Não consta que, para o escritor argentino, profeta da web, refém do presente $^{2}$, existisse algo externo à biblioteca. Ela é, portanto, tudo o que há, tudo o que existe. Entretanto, a biblioteca não passa de palavras, ela não pode

\footnotetext{
${ }^{1}$ In TITAN JR., Samuel. Arsenal coeso e poderoso de idéias. Caderno 2. Cultura. O Estado de S. Paulo, 25 de novembro de 2007. p. D10.

${ }^{2}$ No dizer de Leyla Perrone-Moisés. Caderno 2. Cultura. O Estado de S. Paulo, 25 de novembro de 2007. p. D11.
} 
transcender às possíveis combinações dos vinte e tantos símbolos ortográficos. Ela é apenas linguagem.

Nietzsche aborda este ponto abismal em seu texto "Sobre verdade e mentira no sentido extra-moral": "O que é uma palavra? A figuração de um estímulo nervoso em sons. Mas concluir do estímulo nervoso uma causa fora de nós já é um resultado de uma aplicação falsa e ilegítima do princípio da razão... um estímulo nervoso, primeiramente transposto em imagens! Primeira metáfora. A imagem, por sua vez, modelada em um som. Segunda metáfora (a palavra). Não possuímos nada mais do que metáforas das coisas, que de nenhum modo correspondem às entidades de origem" (Nietzsche, p. 63). Em certo sentido, ao generalizar ainda uma vez o termo tradicionalmente desqualificado - metáfora de forma a inviabilizar a oposição conceito/metáfora, desestabilizando o privilégio atribuído ao conceito, Nietzsche apóia suas reflexões em diversas metáforas, acrescenta que a construção desse domo, do "céu de conceitos", só poderia se sustentar se tramado com fios de aranha, suficientemente delicados para serem levados pelas ondas e sólidos o bastante para não serem dispersados pelo vento.

São essas mesclagens, esses labirintos, essas redes, esses espelhos, essas tramas esgarçadas - outras nem tanto -, essas metáforas, que desafiam e, às vezes, confundem (cum fundĕre). Delicados fios se enredam em tais $\mathrm{p}(\mathrm{I})$ anos discursivo-digressivos e permitem, em certo modo, alçar uma coleção de revistas não só pela mais do que óbvia proposta por seu título: BABEL. Ademir Demarchi, seu editor, questionado a respeito das motivações para se publicar uma revista, responde que publicar uma revista como a Babel é criar focos de resistência e de reflexão sobre esse estado de coisas. Em ensaio no qual avalia o quadro contemporâneo de revistas literárias brasileiras, Maria Lucia de Barros Camargo enquadra a Babel no perfil de "periódicos independentes e de tiragens reduzidas, em que a palavra revista, geralmente no subtítulo, tem o poder e a função de anunciar ao leitor que se trata de uma publicação periódica que não é o jornal, a que se acrescentam seus campos de atuação, distintos, nestes casos, das áreas 
disciplinares constituídas: poesia, cultura, literatura e arte, ou seja, variações sobre o mesmo tema" (2003, p. 22). ${ }^{3}$

A coleção Babel é composta de seis números"; os três primeiros "válidos" por quatro meses, os outros três, anuais. A tiragem do primeiro número foi de 1000 exemplares, do número 2 ao 5, 400, e o número 6 teve tiragem de 500 exemplares.

Nas ilustrações de capa e miolo há temas que são recorrentes: cemitério de trens; a imagem da Torre de Babel (em seu nome: Babel, a ilustração de autoria de Hyeronimus Bosch e a de Gustav Doré); caligrafias, alfabetos, caligramas; "pedaços" do corpo humano... metáforas. Todas remetem a ruínas, os editoriais remetem a ruínas, "restos" do passado. Coleção de objetos do passado que aparecem no presente. Todos elementos de anacronismo. Empresto de Derrida: Des tours de Babel - metáfora razoavelmente adequada para se atribuir às construções e des-construções da revista Babel. Mito da origem do mito. A Torre de Babel não configura apenas a multiplicidade irredutível das línguas, ela exibe um não-acabamento, a impossibilidade de completar, de totalizar, de saturar, de acabar qualquer coisa que seria da ordem da edificação. O que a multiplicidade de idiomas vai limitar não é apenas uma tradução "verdadeira", uma expressão precisa, mas também uma ordem estrutural, uma congruência do constructo, como bem lembra Derrida.

No editorial "Um" (n. 1, p. 4), delimita seu escopo: Babel pisa e re-pisa sobre "as experiências, vistas como ruínas ou não, de 22, de 30, de poéticas consideradas luminares como as de Jorge de Lima, Drummond, João Cabral, Murilo Mendes (coincide com a revista Sibila) - pontos culminantes de uma tradição literária, do concretismo, da poesia marginal dos anos 70 e da nouvelle vague haikaísta disseminada por Leminski”. Arquivo do presente. No entanto, se

\footnotetext{
${ }^{3}$ A autora integraliza o grupo com Sibila - Revista de poesia e cultura; Inimigo Rumor - Revista de poesia; Coyote - Revista de literatura e arte; e a portuguesa Relâmpago - Revista de poesia.

${ }^{4}$ Bilac diria que sofreu do mal-de-sete-números.
} 
se pensar na efemeridade de uma revista, o presente tem dimensão intervalar. Como aponta Virno, o presente instantâneo toma a forma de recordação, é evocado ao mesmo tempo em que se cumpre. Sincrônicos a estas dicções poéticas são presenciais em Babel, entre outros: Glauco Mattoso, Milton Hatoum (como poeta), Valêncio Xavier, Luiz Nazário, Torquato Neto, Waly Salomão... Exemplar do anacronismo (para Virno, formal) presente em Babel é o "Soneto Sortilégio" de Glauco Mattoso (n. 4, p. 45). Mais il ricordo del presente, impossível. Babel antecede o soneto com a seguinte nota explicativa: "Em junho de 2001, ao completar 50 anos, Glauco dedica alguns sonetos a seu companheiro Akira, com quem contrai relacionamento íntimo desde o Natal passado". (n. 4, p. 45)

\section{SONETO SORTILÉGIO}

Chegando ao meio século de vida, me achava, feio e cego, na desdita. Aguardo, em vão: não veio mais visita.

Parece o apartamento muda ermida.

Com Borges tanta coisa é parecida!

Fui bibliotecário; deixo escrita a saga inacabada. Agora dita quem antes anotava, e a consolida.

Que tudo coincide, quem diria?

Se alguém for meu biógrafo, confira:

cegueira, poesia, bruxaria...

Efeito que o feitiço não surtira, enfim surtiu: já tenho companhia...

Em vez duma Kodama, meu Akira! 
Em número anterior da revista, no dossiê sobre o cânone (n. 3), Ricardo Corona, editor da revista Medusa, destaca a descontinuidade do tempo e, de certa maneira, o esgotamento do "novo", do gênero ("Finalmente, nada de novo"). Como paradigma, vale-se da combustão textual de Glauco Mattoso: "Glauco Mattoso derrubou o decreto contra o soneto e, por extensão, através de sua temática baixa, cozida em fôrma alta, borrou os lençóis e travesseiros dos poetas românticos deportados do século passado para os dias de hoje" (p. 116). Em resenha, na Babel n. 1, Camargo assim avaliou a releitura da tradição engendrada por Mattoso: "atualiza pela dissonância com as últimas modas: usa formas clássicas, mas corrompe a idéia de beleza" (p. 123).

Medularmente, a orientação de Babel prima pela multiplicidade de vozes, a pluralidade de línguas e linguagens, proposta apresentada desde o editorial de seu primeiro número: "justamente por primar pela pluralidade... tanto quanto possível pretende ser aberta à poesia que se produz agora... dicções distintas, de outras línguas, outras linguagens...uma revista aberta ao erro e à errância do experimento (e suas grisalhas intenções)... Espaço aberto para a livre manifestação e exposição do que não se publica em outros veículos, alheios a polêmicas" (n. 1, p. 5). Em uma das "salas hexagonais" da Babel, a de Ademir Demarchi $^{5}$, em uma de suas prateleiras, convivem, ou co (n) fundem-se poetas: Sylvio Bach - cineasta consagrado, poeta bissexto, surge em Babel como tradutor; Valêncio Xavier - expert em suturar objetos do passado e do presente numa, digamos, prosa (porque se encaixa na mancha da página) à bric-a-brac; Ademir Assunção - jornalista, letrista da MPB; Jorge Wolff - professor da UNISUL, crítico literário, tradutor... Entre aqueles que a revista "classifica" como de "hoje", nomes que repetem e se repetem na Inimigo Rumor, Medusa, Coyote, e Sibila:

\footnotetext{
${ }^{5}$ Editor da Babel - Revista de Poesia, Tradução e Crítica - Ademir Demarchi (Santos-SP); jornalista, escritor, integra também o Conselho Editorial da Medusa.

Co-editores

Marco Aurélio Cremasco (Campinas-SP); Prof. Eng. Química UNICAMP, poeta

Mauro Faccioni Filho (Florianópolis-SC); Formado em Eng. Elétrica, curtas-metragens, vídeos, poeta. Diretor da Creare

Susana Scramim (Florianópolis-SC); Doutora em Teoria Literária USP, Professora da UFSC
} 
Cláudia Roquette-Pinto, Rodrigo Garcia Lopes, Ricardo Corona, Josely Vianna Baptista, Neuza Pinheiro, Maria Esther Maciel, Cláudio Daniel ... Não é excessivo dizer que a linhagem de escritores presentes em Babel é aquela circunscrita, via de regra, pelo traço, muitas vezes, indissociável entre poesia, crítica e tradução.

Babel - Revista de Poesia, Tradução e Crítica (para não deixar dúvidas, tradução e crítica de poesia) reitera, desde a foto utilizada em sua primeira capa ${ }^{6}$ até entrevista inédita de João Cabral de Melo Neto no último exemplar, um conceito de poesia. "Já é questão assente, também, na literatura, principalmente depois das escritas radicais de Mallarmé, Artaud e Bataille, apenas para ficar nesses três franceses, que 'escrever' é, antes de tudo, 'escrever' contra. Contra o mercado, contra a língua, contra pensamentos fossilizados, estruturados, consolidados" (n. 2, p. 7) A negatividade expõe a medula... A escrita é movida pela insatisfação e para o desmonte. É crítica e busca a distinção. O desvio, gesto desestabilizador, demolidor, é o seu caminho, ainda que não dê em nada ou dê em becos sem saída e por isso mesmo encontra o seu "não-lugar". A reconfiguração: a poesia é negativa porque vai contra a positividade acumulativa da tal lógica de mercado; este (o mercado) ambiciona construir, a outra (a poesia) somente ganha sentido se destruir. "Afinal, se a poesia tem algum papel nesta vida é o de não deixar a linguagem estagnar, deitada em berço esplêndido sobre formas já conquistadas. Sobre clichês. Sobre automatismos. Papel de renovar ou revolucionar o como do dizer" (Leminski, p. 3). Poesia é movimento, não conformismo, inquietação; tudo o que se estabiliza transforma-se em instituição. Cânone? "Somos, em princípio, contra cânones, contudo não cessamos de criar cânones suspeitamente alternativos" (n. 3, p. 75). Para que o movimento seja restabelecido, a poesia deve ser submetida à crise/crítica. "As escolhas feitas por Babel têm procurado contemplar a escrita como insatisfação" (n. 2, p.7).

\footnotetext{
${ }^{6}$ Foto da capa: “Ruínas de um cemitério de elefantrens”, Paranapiacaba-SP, 1999, por Ademir Demarchi.
} 
Revistas gerenciadas por escritores, como a Babel, Inimigo Rumor ${ }^{7}$, Coyote, Medusa, Sibila, entre outras, são arquivos do presente (aliás, diga-se, presente saturado de memória) que têm a função de ignorar a lógica para propor outras concepções de pensamento, trazer à luz o esquecido, situar-se deliberadamente à margem para buscar a inovação ou o diferente em relação ao que se tem como regra corrente. Um dos procedimentos adotados (estratégia de monumentalização, de nobilitação?) é o relevo atribuído a alguns nomes selecionados e (x) citados na capa: Milton Hatoum, Boris Schnaiderman, Langston Hughes e Jeffrey McDaniel (n.1); Glauco Mattoso, Sérgio Rubens Sossélla, Luiz Nazário, Enrique Lihn (n. 2); Torquato Neto, Robert Lowell e Waly Salomão (n. 3); Murilo Mendes, Paulo Franchetti e Poesia de Vanguarda, Ruínas da PósModernidade, Croatas \& Eslovenos (n. 4); Peter Greenaway; Raymond Carver; Raúl Antelo e Davi Arrigucci por Milton Hatoum (n. 5). Fetiche>feitiço>feito. "Fetiche", objeto a que se atribui poder e se presta culto; remonta "feitiço", nome dado ao ídolo pelo próprio adorador, que por sua vez, rememora "feito", o que não é natural, é artificial, é falso, é artefato.

Na tradição - por que não traição? - de trazer à luz o esquecido, enfatizar o desprezado, e/ou situar-se deliberadamente à margem, Babel homenageia Sérgio Rubens Sossélla, citado na capa da n. 2 e presente nas edições 1, 2 e 5. Autor de cerca de 300 títulos, todos com a tiragem reduzidíssima de 10 a 30 exemplares. Sossélla justificava: basta um exemplar enviado a alguém ou colocado numa biblioteca para "tornar público".

Com "nós, gagos de babel, bab amos versos, jorge de lima" há uma evidente presentificação do passado pelo diálogo - ou pelo eco - com as, ditas, poéticas consideradas luminares como as de Jorge de Lima, com os pontos culminantes do concretismo, da poesia marginal dos anos $70 \ldots$

\footnotetext{
${ }^{7}$ Inimigo Rumor - Carlito Azevedo; Coyote - Ademir Assunção, Rodrigo Garcia Lopes; Medusa - Ricardo Corona; Sibila - Régis Bonvicino
} 
nós, gagos de babel, bab amos versos, jorge de lima

nós, gagos de babel, bab amos versos

sós, gagos de babel, babamos versoss

nós, gags o de babel, babamos versos

sós, gagos de babel, babamos versoss

nós, gagos de bel ba, babamos versos

só sâ, gagos de babel, babamos versos

nós, gagos de baabel, babamos versos

sós, gos ga de babel, babamos versos

nós, gagos dde babel, babamos versos

ssós, gagos de babel, babamos versos

nnós, gagos de babel, babamos versos

sós, gagos de babel, babamos versóss

nós, gagos de babel, gabamos ver sos

sós, magos de babel, baba mos versos

nós, gagos de babel, babamos versos,

jorge de lima

sós e nós, gagos de babel, babamos, versos $^{8}$

Se considerarmos que Jorge de Lima presentifica-se como vocativo, a letra ganha mais que simplesmente uma serifa. Mesmo que na minudência, a bordadura de Sossélla reflete (re-flecte) uma trama tecida alhures. Isso equivale, de certa forma, a dizer que "a estratificação folheada, a superimpressão pelicular destas marcas cutâneas parecem desafiar a análise" (Derrida, 2001, p.33).

$\mathrm{Na}$ tradição da tradução, Babel homenageia em editorial José Paulo Paes e Boris Schnaiderman, ambos respeitados tradutores de poesia. Schnaiderman,

${ }^{8}$ Babel n. 1, p. 33 
em entrevista no volume 1, destaca o mérito do poeta Paulo Leminski como tradutor, autor que já havia sido citado como paradigma de poética no editorial da mesma revista. "Rose is a rose is a rose...", diria Gertrude Stein. Nesse movimento labiríntico, o passado retorna e entorna com as traduções de Kobayashi Issa (poeta japonês), Peter Greenaway (cineasta britânico), Konstantinos Kavafis (poeta grego), Langston Hughes (poeta americano), Oscar Wilde (poeta irlandês), Paul Valéry (poeta francês), Elizabeth Bishop (poeta americana), Daniel Link (crítico argentino), Blaise Cendrars (poeta francês)... Poetas traduzem poetas. "A poesia deles confina com os textos que eles traduzem", avalia Susana Scramim, co-editora de Babel, observando a noção de "confim" que Massimo Cacciari desenvolve (p. 67) ${ }^{9}$. O estratagema da tradução revolve e devolve potência à literatura ${ }^{10}$.

Assim, não há como negar que Babel porta-se como enciclopédia ou mosaico a reeditar o início do século XVII, o mundo shakespeariano, a passagem do Renascimento ao Barroco, além de prefigurar uma nova articulação entre cinema e literatura, muito além de simples conjunção de elementos dessemelhantes. Permitida a confluência de tempos, no qual, aliás, poderíamos recuperar a metáfora de Nietzsche lembrada no início deste texto, seu pacifismo é ilusório, vaticina uma cilada aos incautos.

Com base neste tipo de analogia, que acaba investindo também no estranhamento, a tragédia do World Trade Center, refletida por Murilo Mendes em "A catástrofe"11; o incêndio na favela de Vila Socó, em Cubatão, refletida por Marcelo Ariel (poeta humilde de Cubatão) em "Caranguejos aplaudem Nagasaki"12; e o poema de um sem-terra, Valquimar Reis Fernandes ${ }^{13}$

\footnotetext{
9 "Confim, além de ser um limite que nos separa do outro, é o que nos colocaria cara-a-cara com ele por envolver a noção de fronteira, uma vez que o que está na fronteira está próximo, isto é, avizinha-se do outro". (p. 67)

${ }^{10}$ Raúl Antelo refletira sobre a questão em participação na mesa redonda "Que futuro para o passado?", na I Semana Acadêmica de Letras, no dia primeiro de novembro de 2007, no Centro de Comunicação e Expressão, Universidade Federal de Santa Catarina.

${ }^{11}$ Babel n. 5, p. 6

${ }^{12}$ Babel n. 5, p. 82
} 
presentificam a catástrofe, déjà-vu pela sociedade do espetáculo, manipulável segundo os interesses em jogo. No infinitivo impessoal, "presentificar" sugere, seguindo reflexão de Scramim lendo Benjamin, "a posição política de algumas obras do presente de abdicarem definitivamente da característica de "ser arte" (Scramim, 2007, p. 16). Inegavelmente, tais traços, impelem-na em direção ao anacronismo.

Vistas da torre, a linhagem destas revistas franqueia uma via de diálogo com a tradição, profuso exercício do procedimento de montagem em petit pavê, com enfrentamento de discursos intersticialmente - ou confinamento. Centrando em Babel, seu transcurso fecha-se antes e fecha-se depois, em tautocronismo, posto que veículo da literatura do presente, presente, como frisa Virno, visto como se já tivesse sido. Entrelaçamento de potência e ato. As revistas, intérpretes do "no-ya" e do "ahora", traduzidas por objetos do modernariato (em oposição ao antiquariato benjaminiano), excesso de memória que se reproduz, provocam uma espécie de culto por qualquer coisa digna de existir agora, ab aeterno, relevandose seu caráter perenemente transitório. Sendo assim, fetiche, l'objet trouvé (sur réel), colocado em circulação pela e para a literatura do presente.

${ }^{13}$ Babel n. 3, p. 21 


\section{Referências}

BABEL - Revista de poesia, tradução e crítica. Volumes 1 (janeiro a abril de 2000), 2 (maio a agosto de 2000), 3 (setembro a dezembro de 2000), 4 (janeiro a dezembro de 2001), 5 (janeiro a dezembro de 2002) e 6 (janeiro a dezembro de 2003). Coleção completa arquivada na Biblioteca do Núcleo de Estudos em Literatura Comparada - NELIC, CCE, Universidade Federal de Santa Catarina.

BENJAMIN, Walter. O colecionador. In Passagens. Trad. Irene Aron e Cleonice Paes Barreto Mourão. Org. Willi Bolle. Colab. Olgária Chain Feres Matos. Belo Horizonte: Ed. UFMG; São Paulo: Imprensa Oficial, 2006. p. 237-246.

BORGES, Jorge Luis. Ficções. Trad. Davi Arrigucci Jr. São Paulo: Companhia das Letras, 2007. (Coleção Biblioteca Borges)

CAMARGO, Maria Lucia de Barros. Paulisséia ilhada. Sonetos tópicos. In Babel - Revista de poesia, tradução e crítica. n. 1. janeiro a abril de 2000. p.118123.

- Sobre revistas, periódicos e qualis tais. In Outra travessia Revista de literatura. Ilha de Santa Catarina, Pós-graduação em Literatura, Universidade Federal de Santa Catarina. n. 40/1. 2. semestre de 2003. p. 21-36.

CORONA, Ricardo. Finalmente, nada de novo. In Babel - Revista de poesia, tradução e crítica. n. 3. setembro a dezembro de 2000. p.115-116.

DEMARCHI, Ademir. www.revistazunai.com.br/depoimentos_debates/pq_editar_revista_ literaria_hoje. htm, acesso em 30/1/2008.

DERRIDA, Jacques. Mal de arquivo: uma impressão freudiana. Trad. Cláudia de Moraes Rego. Rio de Janeiro, Relume Dumará, 2001. . Torres de Babel. Trad. Junia Barreto. Belo Horizonte, Ed. UFMG, 2002.

FONTES, Luísa Cristina dos Santos. Roteiro para o Seminário sobre revistas contemporâneas, apresentado em novembro de 2007. Curso: Em revista: poesia e crítica de poesia, Disciplina: Poesia brasileira contemporânea, ministrado pela Profa. Dra. Maria Lucia de Barros Camargo. 
GREENAWAY, Peter. Roteiro de Prospero's Books. Trad. de Maria Esther Maciel. Babel - Revista de poesia, tradução e crítica. n. 5. 2002. p. 57-63.

LEMINSKI, Paulo. O veneno das revistas da Invenção. In Folhetim, n. 278, Suplemento do jornal Folha de S. Paulo, de 16 de maio de 1982. p. 3.

NIETZSCHE, Friedrich. Sobre verdade e mentira no sentido extra-moral. In: Obras incompletas. Trad. Rubens Rodrigues Torres Filho. São Paulo: Ed. Nova Cultural, 1996. (Coleção Os Pensadores)

SCRAMIM, Susana. Literatura do presente: história e anacronismo dos textos. Chapecó, Argos, 2007.

VIRNO, Paolo. El recuerdo del presente: ensayos sobre o tiempo histórico. Trad. Eduardo Sadier. Buenos Aires, Paidós, 2003.

WILLIAMS, Raymond. Cultura. 2.ed. Trad. Lólio Lourenço de Oliveira. São Paulo, Paz e Terra, 2000. 